\title{
João Cabral de Melo Neto: $O$ erudito severo versus o popular Severino
}

Cláudia Coelho ${ }^{1}$

RESUMO: Desde a maneira como foi concebida até o caminho que percorreu para chegar ao estrondoso sucesso, tudo propiciou a identificação da obra Morte e vida severina com o grande público, tanto pela encenação teatral como pela adaptação teledramatúrgica. Dessa forma, o texto aborda os aspectos internos e externos que fazem essa obra transitar pelas culturas erudita, popular e de massa.

ABSTRACT: Since the way was conceived by the way that traveled to get to the overwhelming success, it provided the identification of the work Morte e vida Severina with the general public, both by the theatrical staging and the adaptation for film and television. Thus, the text addresses the internal and external aspects that make this work carried by cultures erudite, popular and mass.

PALAVRAS-CHAVE: Cultura de massa; Cultura popular; Cultura erudita; Regionalismo;Universalidade

KEYWORDS: Mass culture; Popular culture; Erudite culture; Regionalism; Universality

O conjunto da obra de João Cabral é conhecido nos meios eruditos e populares pela qualidade artística, mas ainda é um desafio falar de cultura de massa relacionando-a com João Cabral de Melo Neto. Conhecida pela sua racionalidade, pela forma altamente cerebral com que é construída, dificilmente sua poética será eleita "livro de cabeceira" do leitor médio. Houve, porém, uma composição poéticodramática que aproximou esse poeta das camadas populares e que se tornou fenômeno de mercado, levando ao conhecimento das massas parte da obra cabralina. Esta obra é Morte e vida Severina - Auto de

1 Doutoranda em Estudos comparados de literaturas de língua portuguesa (USP, FFLCH). Título da pesquisa: A arquitetura do poema em João Cabral de Melo Neto e Carlos de Oliveira: singularidades da forma e do sentido.

Email: carneirocoelho@superig.com.br. 
natal pernambucano. Escrita em 1954, desde a maneira como foi concebida (a partir de uma encomenda de Ana Maria Machado, fazendo várias referências à cultura popular ibérica e nordestina), até o caminho que percorreu para chegar ao estrondoso sucesso, tudo propiciou a sua identificação com o grande público, chegando a ter se transformado, em parte, num grande sucesso da Música Popular Brasileira, após ter sido musicada por Chico Buarque de Hollanda.

O grande sucesso mercadológico, que é a obra Morte e vida Severina, foi composto por um poeta erudito, consagrado pela crítica como um cânone da literatura brasileira, e que cria poemas como quem trabalha arduamente na construção de um edifício, sob o sol do meiodia, sem deixar que haja interferência da inspiração momentânea e da sentimentalidade na arquitetura da obra, extremamente racionalizada na busca da síntese e do amalgamento perfeito.

Antes de escrever Morte e vida Severina, João Cabral já havia publicado várias outras obras que utilizam como motivo poético sua terra natal - Pernambuco. Dela o poeta destaca a imagem do rio Capibaribe, motivo de duas outras obras, além do próprio auto de natal. A primeira é O cão sem plumas, publicado em 1950, em Barcelona, no qual temos a relação metafórica de um rio estagnado, estéril, seco, avesso à abundância e fecundidade própria desse tipo de imagem. Como o "cão-rio" sua poesia também é desprovida de "plumas"; o rio inesperado do poeta lembra o rigor obstinado a que submete sua obra. Após quatro anos sem publicar, em 1954, já em São Paulo, vem à luz a obra O rio ou Relação da viagem que faz o Capibaribe de sua nascente à cidade do Recife; desta vez o poeta dá voz ao próprio rio Capibaribe, num processo de antropomorfização. Desaparece nesta obra o caráter simbólico que se revestia $O$ cão sem plumas. Em $O$ rio temos um eu impassível que registra o movimento que o olhar vai captando, não só da paisagem física mas também do elemento humano da região. Tratase de uma descrição objetiva, quase que literal, que filia-se à "segunda água”, ou à categoria do “dizer”, segundo palavras do próprio poeta. 
João Cabral, em 1954, numa tese exposta no Congresso Internacional de Escritores, em São Paulo, cujo título foi $D a$ função moderna da poesia, abordou a "incomunicabilidade reinante na poesia contemporânea e a dificuldade dos poetas modernos em atingir um público mais amplo para seus textos” (Barbosa, 1996. p. 06). Falou ainda que o progresso obtido na área limitava-se apenas à parte de registro da expressão poética, mas não atingia a "contraparte orgânica a comunicação", havendo muito pouco esforço no sentido de utilização do rádio, televisão ou cinema em favor de sua divulgação. Eis algumas de suas palavras:

A poesia moderna - captação da realidade objetiva moderna e dos estados de espírito do homem moderno - continuou a ser servida em invólucros perfeitamente anacrônicos e, em geral imprestáveis, nas novas condições que se impuseram (MELO NETO, 1994. p. 769).

E, mais adiante, acrescenta:

No plano dos tipos problemáticos, tudo o que os poetas contemporâneos obtiveram, foi o chamado "poema" moderno, esse híbrido de monólogo interior e de discurso de praça, de diário íntimo e de declaração de princípios, de balbucio e de hermenêutica filosófica, monotonamente linear e sem estrutura discursiva ou desenvolvimento melódico, escrito quase sempre na primeira pessoa e usado indiferentemente para qualquer espécie de mensagem que o seu autor pretenda enviar. Mas esse tipo de poema não foi obtido através de nenhuma consideração acerca de sua possivel função social de comunicação. $O$ poeta contemporâneo chegou a ele passivamente, por inércia, simplesmente por não ter cogitado do assunto. Esse tipo de poema é a própria ausência de construção e organização, é o simples acúmulo de material poético, rico, é verdade, em seu tratamento do verso, da imagem e da palavra, mas atirado desordenadamente numa caixa de depósito ( 1994. p. 769-770).

Dessa forma, o escritor defende o fazer que não se atém apenas no acúmulo de material poético, mas que busca novas formas de comunicar-se com o leitor. Nesta tese, Cabral deixou claro que não pretendia escrever apenas para a pequena minoria de letrados, mas 
desejava atingir também o público médio, e a maneira de se conseguir esse objetivo era através da utilização dos meios de massa.

No mesmo ano de 1954, atendendo a um pedido de Maria Clara Machado, filha de Aníbal Machado, escritor e amigo do poeta, e diretora do Grupo de Teatro O Tablado, que encomendou-lhe um auto de natal para encenar, Cabral começa a escrever Morte e vida severina.

Em 1956, o poeta publica o volume Duas águas, em que mescla algumas obras já publicadas anteriormente com inéditas, entre essas Morte e vida severina. Notadamente, as obras em que o rio Capibaribe é imagem recorrente encaixam-se na categoria do dizer, pois têm mais apelo popular. A divisão de sua obra em duas vertentes vem colocar em prática a preocupação com a indiferença dos poetas modernos em relação à comunicabilidade de sua poesia, pois direciona a categoria do dizer a um grande público.

Para composição dessa obra, Cabral recorreu a um livro sobre o folclore pernambucano, de autoria de Pereira da Costa, e também à antiga poesia ibérica, com a qual teve contato durante o exercício de função diplomática na Espanha:

Esse texto não poderia ser mais denso. Era obra para teatro, encomendada por Maria Clara Machado. Foi a coisa mais relaxada que escrevi. Pesquisei num livro sobre o folclore pernambucano, publicado no início do século, de autoria de Pereira da Costa. Eu era consciente de que não tinha tendência para o teatro, não sabia criar diálogos no sentido da polêmica. Meus diálogos vão sempre na mesma direção, são paralelos. Observe o episódio das pessoas defronte do cadáver: todos trazem uma imagem para a mesma coisa. A cena do nascimento, com outras palavras, está em Pereira da Costa. "Compadre, que na relva está deitado" é transposição deste folclorista, pois no Capibaribe há lama, e não grama. "Todo céu e terra lhe cantam louvor" também é literal do antigo pastoril pernambucano. O louvor das belezas do recém-nascido e os presentes que ganha existem no pastoril. As duas ciganas estão em Pereira da Costa, mas uma era otimista e a outra pessimista. Eu só alterei as belezas e os presentes, e pus as duas ciganas pessimistas. Com Morte e Vida Severina, quis prestar uma homenagem a todas as literaturas ibéricas. Os monólogos do retirante provêm do romance castelhano. A cena do enterro na rede é do folclore catalão. $\mathrm{O}$ encontro com os cantores de incelências é típico do Nordeste. Não me lembro se a mulher da janela é de origem 
galega ou se está em Pereira da Costa. A conversa com Severino antes de o menino nascer obedece ao modelo da tenção galega (In: BARBOSA, 1996. p. 05).

Como pudemos constatar com palavras do próprio autor, foi um texto composto de forma mais relaxada, sem preocupar-se tanto com o cerebralismo, o rigor matemático e arquitetônico com que compôs a maioria de suas obras. Frederico Barbosa (1996) assevera que, além das influências comentadas pelo autor na citação acima, também é clara a influência do romance regionalista de 30 , que se voltou para a abordagem crítica da realidade sertaneja:

O que João Cabral de Melo Neto conseguiu com Morte e Vida Severina foi exatamente colocar uma inteligência mais requintada a serviço do regionalismo, revelando para o mundo aspectos despercebidos da realidade nordestina e brasileira (BARBOSA, 1996. p. 06).

É interessante notar que a obra, que para o autor foi a mais relaxada que escreveu, analisada em comparação às outras obras regionalistas que a precederam, é considerada um trabalho de "inteligência mais requintada", portanto Morte e vida severina é um texto relaxado para os padrões cabralinos rigorosos, mas não em comparação a outros textos de outros autores brasileiros.

Apesar de confessar-se despreparado para escrever texto dramático, o autor fez várias pesquisas sobre a cultura popular de seus conterrâneos, assim como buscou embasamento no padrão dramático medieval de auto. Desde a estrutura formal percebe-se a referência do popular na obra: os versos são, em sua maioria, redondilhos. A medida velha utilizada por Gil Vicente remete à cultura popular medieval e também à tradição oral nordestina.

Mas não é só na estrutura que tais intertextos são notados; em toda a obra há uma riqueza simbólica presente: as figuras de linguagem dão dramaticidade ao poema. São freqüentes as metáforas, que são utilizadas para a construção do Severino, alegoria dos marginalizados. Sua viagem, que por sua vez é também uma metáfora dos retirantes e 
sua luta pela sobrevivência, é carregada de imagens metafóricas. O rio Capibaribe, motivo poético já utilizado pelo autor, metaforiza um fio de vida que vai minguando e assusta o retirante, provocando nele o medo de perder o seu guia, o medo de romper-se o frágil fio que o liga à vida. É bastante antiga a tradição de nortear o caminho seguindo a trajetória de um rio: Almeida Garret (1983), na obra Romanceiro, apresenta um romance medieval cujo personagem, o cavaleiro de Avalor, viaja sozinho e sem esperanças seguindo a margem de um rio; também o lavrador abandonado por Deus, vítima da miséria social, já havia sido tema dos autos de Gil Vicente. Cabral, porém, não ridiculariza seu personagem, como o faz Gil Vicente, e sim dá-lhe conotação trágica, sem com isso cair no melodrama. Outro aspecto a ser observado é que tanto na cultura medieval quanto na nordestina há uma forte influência do mundo religioso, presente (desde o subtítulo da obra: Auto de Natal Pernambucano) em todo seu percurso, tanto de morte como de vida: o rio-estrela-guia; as contas do rosário; os cânticos fúnebres, o presépio; o nascimento de Jesus (filho de São José, que era carpinteiro). Mas em João Cabral essa religiosidade aparece apenas como retrato fiel da realidade cultural do povo nordestino, não provocando alienação do texto, que é altamente racional:

Para João Cabral, a poesia é imagem à cata da realidade, é palco à espera do drama humano. O poema não se passa no interior do indivíduo, mas numa arena pública onde o homem enfrenta com engenho e destemor o seu maior desafio: a morte. (...) Cultua-se a busca de Vida em tempos de miséria humana e morte (SANTIAGO, 2006. p. 01).

A encomenda deste trabalho parece ter vindo a calhar com o discurso no Congresso Internacional de Escritores; foi uma oportunidade para o poeta escrever algo que possibilitasse o acesso do público à poesia moderna. Apesar do fato de Maria Clara, quando o poeta entregou-lhe a obra pronta, em 1955, ter-lhe devolvido o texto, dizendo que não servia para o propósito ao qual foi destinado, João Cabral resolveu “aproveitar o texto" para "dar volume” à sua primeira 
antologia poética: em 1956, publica, pela José Olympio, o livro Duas águas, que contém os livros anteriores mais três inéditos: Uma faca só lâmina, Paisagens com figuras e o tema de estudo deste trabalho: Morte e Vida Severina. Este, juntamente com O Rio e Os três mal-amados pertence à segunda água:

Duas águas querem corresponder a duas intenções do autor e decorrentemente - a duas maneiras de apreensão por parte do leitor ou ouvinte: de um lado, poemas para serem lidos em silêncio, numa comunicação a dois, poemas cujo aproveitamento temático, quase sempre concentrado, exige mais do que leitura, releitura; de outro, poemas para auditório, numa comunicação múltipla, poemas que, menos que lidos, podem ser ouvidos. (MELO NETO, apud NUNES, 1974. p.74).

Benedito Nunes (1974) relacionou a segunda água à preocupação do autor com a comunicabilidade da poesia moderna:

É precisamente sob o aspecto de comunicação, problema que tanto preocupa João Cabral, (...), que a diferença entre as "duas águas” pode ser estabelecida. Não é a quantidade de informação nem as qualidades formativas da poesia que estão em jogo na "segunda água", mas o aumento do volume e da área de sua comunicabilidade. Temos assim, em vez de duas espécies de poesias, dois tipos de dicção que se distinguem em função do destinatário e da modalidade de consumo do texto (NUNES, 1974. p.74).

Podemos perceber que o autor fala sobre seu auto com certo desdém, afirmando que só o publicou "para dar volume”. É clara sua opinião de que esse texto merecia ter passado por revisões, a exemplo das outras obras, pois esse sempre foi seu método de composição. Todavia, desta vez não houve tempo para tais retoques, pelo fato do auto ter sido encomendado, com prazo de entrega, e, após entregue, o autor não ter se sentido mais à vontade para mudá-lo. Para João Cabral, a obra, após ser conhecida, é como se tivesse sido embalsamada, e qualquer mudança que venha a sofrer a tornará outra obra, sem, contudo, deixar de existir a anterior: 
Maria Clara Machado me encomendou um "Auto de Natal”. Eu me lembrei de uns Autos Pastoris que havia em Pernambuco no século passado, e fiz aquilo em cima de um tema que basicamente está em todos os escritores do Nordeste, que é o problema do retirante. Aquilo está em José Lins do Rego, em Graciliano Ramos, em Jorge Amado, em Rachel de Queiroz... Não havia muita novidade naquela coisa do retirante que vem do sertão procurando trabalho aqui nos centros urbanos. Agora, quando digo que aquela obra não me satisfaz, é o seguinte: como foi uma coisa encomendada, não tive tempo de trabalhar tanto quanto gostaria, compreende? $\mathrm{E}$ depois que entreguei, achei que já havia entregue e... nada poderia fazer pra mudar, e ficou assim mesmo. O José Olympio ia publicar minhas poesias completas até então, um livro que ia sair das minhas obras. Para engrossar, inseri aquilo nas obras; para engrossar um pouco o livro, incluí o meu auto. ${ }^{2}$

A reação estupefata do poeta em relação à grande aceitação da obra por parte de intelectuais ficou clara quando Vinicius de Moraes o procurou para elogiar o auto:

Foi uma surpresa quando encontrei com Vinicius de Moraes no Rio e ele me disse: "Joãozinho, estou maravilhado com Morte $e$ Vida Severina". Aí eu não entendi nada. "Vinicius, eu não escrevi Morte e Vida Severina para intelectuais como você", respondi. "Escrevi para os sujeitos analfabetos que ouvem cordel na feira de Santo Amaro, no Recife".

O poema é simples, retrata a típica realidade do pernambucano que foge da seca em busca do Recife e termina morando numa favela ribeirinha. Foi um sucesso mundial. Isso me orgulha, mas também me surpreende porque Morte $e$ Vida Severina passou a ser coisa de eruditos (MELO NETO, 2006, p. 01).

O arrependimento do poeta pela forma precipitada, volto a frisar, segundo seus padrões rigorosos de composição, com que veio a público a obra iria ficar mais explícito dez anos depois. A comunicabilidade da segunda água cabralina iria encontrar seu mais alto representante nesse texto. Em 1966, a obra foi encenada no TUCA, teatro da Pontifícia Universidade Católica de São Paulo, e contou com a direção de Silney Siqueira, adaptação de Roberto Freire, música de Chico Buarque de

\footnotetext{
2 Trata-se de um trecho de entrevista de João Cabral de Melo Neto veiculada no site http://medei.sites.uol.com.br/penazul/geral/entrevis/cabral.htm, onde não consta o nome do entrevistador ou profissional responsável pela matéria.
} 
Holanda e o ator Paulo Autran no elenco. O espetáculo tornou-se um marco na história do teatro brasileiro, tendo sido encenado em várias cidades do país.

O sucesso que obteve, tanto a apresentação da peça, como o trecho do poema musicado por Chico, tornou o poeta João Cabral conhecido do grande público, mas nem por isso assimilado.

Por essa época o poeta havia sido designado como ministro conselheiro e muda-se para Berna, onde recebe um pedido de autorização para que o grupo de teatro do TUCA montasse a peça. O autor fez questão de viajar para acompanhar a apresentação do espetáculo em Nancy, na França:

Eu estava em Berna quando eles foram para Nancy. Fui de Berna para Nancy para ver a estréia da peça, e fiquei emocionado. Aliás, na estréia deles, quem fez o Severino foi um rapaz que morreu naquele incêndio do Edifício Joelma, um rapaz do Maranhão. Eu estava em Berna quando um amigo meu me escreveu dizendo que eles me pediam licença para fazer a peça, no teatro da Universidade Católica de São Paulo, que era o auto Morte e Vida Severina, musicada por Chico Buarque de Hollanda, filho do Sérgio (eu conhecia o pai dele) e estudante de arquitetura na Universidade Católica de São Paulo. Ele fazia parte do grupo e fez a música. 3

Esta apresentação rendeu-lhe o Prêmio de Melhor Autor Vivo, concedido no Festival Universitário de Teatro. Após o Festival de Nancy, o espetáculo foi encenado no Théatre des Nations, em Paris e, posteriormente, em Lisboa, Coimbra e Porto.

Embora em diversas oportunidades o poeta tenha destacado sua inaptidão para a música, João Cabral reconheceu mais tarde a qualidade do trabalho de Chico Buarque ao musicar um trecho de sua obra, chegando a declarar que não conseguia mais distanciar os versos por ele feitos da música que lhe imprimiu o compositor

Nesta oportunidade, João Cabral aproveita para assumir sua admiração pelas composições dos cantores do movimento tropicalista: "Você sabe que não sou muito de música, mas o que acho interessante

\footnotetext{
${ }^{3}$ Idem.
} 
nestes compositores é como melhorou a qualidade da letra". ${ }^{4}$ Esses artistas desenvolveram um trabalho de grande criatividade $\mathrm{e}$ racionalismo, superando qualitativamente os artistas da MBP que os precederam: "Veja um Caetano Veloso, um Chico Buarque, um Gilberto Gil. Veja que a letra deles tem uma qualidade muito superior de música popular do que se fazia antigamente". 5

Em 1969, a Companhia Paulo Autran viajou diversas cidades brasileiras apresentando a mesma peça. Após o sucesso da montagem do espetáculo, no caminho rumo ao público de massa, a obra encontraria cada vez mais condutores: O auto de natal pernambucano virou filme dirigido por Zelito Vianna, em 1976, sob o título de Morte e vida severina: um filme documento. O papel de Severino ficou por conta do ator José Dumont, que mais tarde iria fazer o mesmo papel na TV. O filme inicia-se com uma apresentação teatral, em estilo popular mambembe, de trechos do auto. Depois Zelito faz um documentário sobre o percurso do Rio Capibaribe, da nascente até Recife, utilizando como fundo trechos do poema O rio. Há outro documentário que enfoca depoimentos de nordestinos falando sobre as dificuldades $\mathrm{e}$ compensações da vida. Em contraste aos documentários, José Dumont representa o drama de Severino.

É um filme sério e honesto, mas não bom. É prejudicado por graves problemas técnicos. O som é quase inaudível, uma crítica histórica que sempre se fez ao cinema brasileiro e, aqui, é procedente. Perde-se a grandeza do texto (MERTEN, 1999).

Não é grande, proporcionalmente à população do país, o público que tem acesso aos espetáculos teatrais. Morte e vida severina, porém, conseguiu atrair o maior número de pessoas possível nas cidades por onde foi encenada, tendo obtido também um alto índice de "aprovação". A Gravadora Caritas lançou o disco Morte e vida severina, em 1967, com trechos do espetáculo e então música de Chico Buarque virou

\footnotetext{
4 idem.

5 idem.
} 
grande sucesso da MPB. Dessa forma, a obra de João Cabral penetrou em meios populares que até então não a conhecia. O filme de Zelito Vianna também teve repercussão imediata pelo país, impulsionado pela fama do espetáculo teatral, a despeito de seus problemas técnicos.

Mas o que projetou definitivamente João Cabral aos meios massivos foi o programa especial de fim de ano exibido pela Globo em 1981. A TV, de alcance nacional, realizou um especial dirigido por Valter Avancini, cujas cenas puderam contar com a tecnologia de ponta, na época, de equipamentos portáteis que possibilitavam a gravação de cenas externas com boa qualidade de vídeo e áudio:

O especial de TV tem som perfeito e plasticidade impecável. Foi o primeiro especial que a Globo gravou em locações. Quando se fala em Avancini como o papa da TV brasileira, é em obras como essa que se deve amparar para a afirmação (MERTEN, 1999).

Rapidamente a emissora vendeu cópias da obra para os Estados Unidos e alguns países da Europa. A minissérie rendeu-lhe, em 1982, o prêmio Ondas e também o Emmy, espécie de Oscar da TV americana. O trabalho foi considerado a obra mais densa produzida pela TV brasileira. O ator José Dumont, intérprete de Severino, em entrevista a Rosa Menine, disse ter sido uma produção extraordinária, "Essa obra ficou gravada na memória de quem viu. Em termos de valor, não se discute", diz. O ator fala ainda que, para a TV Globo, a minissérie foi decisiva. Na época, a emissora não era hegemônica e precisava de bons trabalhos para entrar no mercado mundial.

Além de José Dumont, participaram das gravações os atores Tânia Alves, Paulo Gracindo, Jofre Soares e Elba Ramalho, que na minissérie interpretou a canção de Chico Buarque, assimilada como uma espécie de hino do movimento pró reforma agrária.

Essa conotação ideológica irritou bastante o poeta, principalmente na época das apresentações teatrais. João Cabral não admitia que a literatura precisasse ser engajada para ter valor, por isso 
perseguiu a sua vida toda a poesia pura. Daí seu descontentamento com a forma que foi recebida pelo público a sua obra:

O que me chateou muito também a respeito do sucesso mundial de Morte e Vida Severina foi que a burrice nacional brasileira começou a fazer inferências políticas sobre o poema. Muita gente queria que depois de cada espetáculo eu subisse ao palco e gritasse "Viva a Reforma Agrária". Recusei-me a fazer isto. Não faço teorias para consertar o Brasil, mas não me abstenho de retratar em poesia o que vejo e sinto. Eu mostrei a miséria que havia no Nordeste. Cabia aos políticos cumprirem seu papel. Essas exigências de engajamento político me irritaram muito. Ainda bem que logo depois fui para Sevilha, Genebra, Assunção e fiquei muito tempo longe do Brasil. Foi o tempo necessário para que parassem de achar que eu deveria fazer arte engajada em vez de poesia pura (MELO NETO apud BARBOSA, 1996. p. 06).

Esse foi o caminho percorrido por Morte e vida severina: Do livro saltou para os palcos, depois para os discos, para as telas de cinema e finalmente para a televisão, derrubando as fronteiras que separam a obra de arte do público com a larga utilização das "armas” audiovisuais. Silviano Santiago, em seu ensaio intitulado Comparações, assim define a relação da poética cabralina com os meios massivos:

Essas comparações ensinam muitas coisas e ensinam sobretudo que a melhor poesia contemporânea não é preconceituosa. Não se entronizou a si mesma no monte Parnaso e, por isso, não ficou alheia a outros meios de expressão estética, nem mesmo àqueles meios que, pela reprodutibilidade técnica ou pelo lado espetacular, se dirigem às grandes massas, como é o caso do cinema (...) (SANTIAGO, 2006. p. 01).

Embora João Cabral tenha demonstrado desejar que sua poesia chegasse a um grande número de leitores e/ou ouvintes, e de ter consciência que é impossivel ao poeta prever quais os efeitos que um poema pode causar em seus diversos leitores, sua frustração com o sucesso deve-se ao fato de ter constatado que o público não assimilara o que havia de melhor em sua obra, realizando leituras superficiais e muitas vezes distorcidas. Desde que foi publicada, Morte e vida Severina foi a grande responsável pelo aumento do volume de vendas de seus livros. Mesmo antes de se tornar espetáculo, filme e minissérie, de 1956 
a 1966, Duas águas bateu o recorde de vendas de suas obras anteriores. As demais edições individuais ou coletâneas, nas quais estava incluído o auto, tiveram grande sucesso de vendagem. Os outros títulos do autor também tiveram um aumento considerável de aceitação no mercado, porém o autor nunca se iludiu com o fenômeno de vendagem:

O que acontece é que no Brasil, depois que você chega a certa idade e cria um nome, compram seu livro, não para ler, compram seu livro para botar na estante e para dizer que compraram (MELO NETO apud MARTINS, 1999).

Em 1966, mesmo ano da estréia da peça no teatro, João Cabral chega ao ápice de sua produção literária: Após cinco anos sem publicar, vem a lume $A$ educação pela pedra, obra com bases na disciplina, no rigor formal e anti-sentimental, "contendo o ideal poético de contenção e impessoalidade, de petrificação ou mineralização das palavras, e o ideal ético de resistência fria, de dureza obstinada e agressiva (...)" (NUNES, 1971), realizando de forma mais plena o ideal de poesia que o escritor perseguiu desde a juventude. Por tudo isso essa deveria ser a obra que o projetaria como grande poeta brasileiro. Todavia, ocorreu o processo inverso e sua obra mais "relaxada" - Morte e vida severina - passou a ser o ícone da poética cabralina, não só nos meios de massa, como também para grande parte dos intelectuais.

Todas as obras de João Cabral são alvo de inúmeros estudos acadêmicos. Sua fortuna crítica é imensa. Seus estudiosos não hesitam em ressaltar a qualidade de sua poesia, que, desde o primeiro livro, Pedra do Sono, já continha a severidade rigorosa da contenção poética e da concretude das imagens. Seu nome, porém, até hoje está irremediavelmente ligado a uma só obra: Morte e vida severina. Com certeza esta é a obra de João Cabral de Melo Neto mais conhecida pela grande maioria dos brasileiros. Ela conseguiu agradar tanto o crítico mais preparado quanto o público que procura entretenimento na literatura. E isso não é por acaso; no texto, encontram-se todas as 
imagens que representam a poética do autor: a secura, a pedra, a magreza, a dificuldade. Todavia tudo isso nos é apresentado através da fala simples de um Severino coletivo, no gênero dramático que propicia o envolvimento do leitor/ouvinte. Se este auto é o que menos corresponde ao ideal poético de Cabral, é ele que conseguiu realizar uma de suas importantes metas: tornar a poesia acessível, comunicável. Com a ajuda dos meios audiovisuais, o texto cabralino chegou a todos os cantos do Brasil e a muitos do mundo.

\section{Referências bibliográficas}

ATHAYDE, Félix de (org.). Idéias fixas de João Cabral de Melo Neto. Rio/Mogi das Cruzes: Nova Fronteira/FBN/Universidade de Mogi das Cruzes, 1998.

BARBOSA, Frederico. O Poeta do Rigor: João Cabral de Melo Neto. In: Diário do Grande ABC: Caderno Cultura \& Lazer, São Paulo, p. 3, 11 nov. 1999.

BENJAMIN, Walter. A obra de arte na época de suas técnicas de reprodução. In: __ et alli. Textos escolhidos. Trad. José Lino Grünnewald. 2 ed.

São Paulo: Abril Cultural, 1983. (Os pensadores).

BOSI, Alfredo. Cultura brasileira e culturas brasileiras. In: Dialética da colonização. São Paulo: Companhia das Letras, 1992. p. $308-345$.

ECO, Umberto. Cultura de massa e "níveis" de cultura. In: Apocalípticos e integrados. 6 ed. São Paulo: Perspectiva, 2001. p. 33-67.

GARRETT, Almeida. Romanceiro. Lisboa: Europa-América, 1993.

HORKHEIMER, Max. ADORNO, Theodor W. A indústria cultural: O iluminismo como mistificação das massas. In: LIMA, Luiz Costa. Teoria da cultura de massa. Rio de Janeiro: Saga, s/d. p. 157-202.

MARTINS, Wilson. Cabral por ele mesmo. In: O Globo: Cad. Prosa e Verso. Rio de Janeiro, p. 05, 23 jan. 1999.

MELO NETO. João Cabral. Morte e vida Severina e outros pomas para vozes. Rio de Janeiro: Nova Fronteira, 1997.

. Duas águas. Rio de Janeiro, José Olímpio, 1956.

. Obra completa. Rio de Janeiro: Nova Aguilar, 1994.

MERTEN, Luiz Carlos. A vida severina chegou às telas. Jornal do Comércio: Cadernos Especiais. Recife, 11 out. 1999.

MOISÉS, Carlos Felipe. João Cabral de Melo Neto. In: Poetas do Modernismo. v. 6. Brasília: INL/MEC, 1972. (Coleção de Literatura Brasileira 9E)

MORIN, Edgar. A integração cultural. In: Cultura de massas no século XX: O espírito do tempo - I: Neurose. 4 ed. Rio de Janeiro: ForenseUniversitária, 1977. p 11-85.

NUNES, Benedito. João Cabral de Melo Neto. Petrópolis: Vozes, 1971.

SECCHIN, Antonio Carlos. João Cabral: A poesia do menos. São Paulo: Duas Cidades; Brasília: INL, Fundação Nacional Pró-Memória, 1985. 


\section{Referências eletrônicas:}

BARBOSA, Frederico. Severina. São Paulo: Anglo, 1996. Disponível em: http://www.secrel.com.br/jpoesia/fred01.html. Acesso em 23 jun. 2004.

MELO NETO. João Cabral de. João Cabral: O engenheiro do verso. Entrevista. Disponível em: http://medei.sites.uol.com.br/penazul/geral/entrevis/cabral.htm. Acesso em 13 ago. 2006. - Gênese $e$ influências. Disponível no site: http://www.ensaioaberto.com/genese_e_influencia.htm. Acesso em 08 jul 2007.

MININE, Rosa. O realismo popular de José Dumont. Disponível em: http://www.anovademocracia.com.br/31_12.htm. Acesso em 20 jun. 2007.

SANTIAGO. Silviano. Comparações. Disponível em: http://www.tanto.com.br/silvianodois.htm. Acesso em 08 jan. 2006. 